\title{
OCLUSÕES ARTERIAIS DO SISTEMA CARÓTIDO-VERTEBRAL. PROBLEMAS DO DIAGNÓSTICO ANGIOGRÁFICO
}

\author{
JosÉ ZaCLIS * \\ O. RICCIARDI CRUZ**
}

Os conhecimentos relativos à trombose da artéria carótida interna tomaram considerável impulso com a descoberta e divulgação da angiografia cerebral. De achados de necropsia motivando ulteriores correlações anátomo-clinicas ${ }^{4}$, as oclusões das carótidas e de seus principais ramos passaram a constituir entidades diagnosticáveis em vida.

No início desta nova fase, os estudos visaram estabelecer as bases para o diagnóstico, mediante correlação dos achados angiográficos com as manifestações clínicas 3, 6; êstes estudos baseados na correlação angiográfico-clínica trouxeram pouco progresso no tocante aos conhecimentos já obtidos mediante a correlação anátomo-clínica quanto às conseqüências clínicas das oclusões arteriais. Recentemente, alguns autores se preocupam com o restabelecimento da corrente sangüínea em vaso ocluido por trombo, mediante intervenção cirúrgica ${ }^{2,7}$. Diversos tipos de operação têm sido preconizados com maior ou menor entusiasmo ${ }^{1,2,9}$.

A par das dificuldades técnicas por vêzes intransponíveis ${ }^{9}$, a avaliação dos resultados dessas intervenções é difícil, pôsto que, na maior parte dos acidentes vasculares cerebrais a que os pacientes sobrevivem, há tendência à regressão dos sintomas em maior ou menor grau, não raro até à recuperação integral ${ }^{10}$. Quando, após desobstrução cirúrgica de uma artéria, a sintomatologia se atenua e a angiografia mostra restabelecimento da corrente sangüínea no vaso operado, os entusiastas não vacilam em atribuir à desobstrução arterial a melhora clínica do paciente ${ }^{2,4}$. Entretanto, não é raro que, após regressão dos sintomas em um paciente que fôra operado, a angiografia mostre que $o$ ato cirúrgico na realidade não desobstruíra a artéria visada 5 . Isto sugere que entre o restabelecimento do fluxo sangüíneo no vaso operado e a regressão eventual das manifestações clínicas não existe obrigatòriamente relação de causa e efeito.

Neste trabalho procuraremos focalizar dados que permitam avaliar melhor os resultados da cirurgia vascular cerebral. É evidente que na apre-

Trabalho da Clínica Neurológica da Fac. Med. da Univ. de São Paulo (Prof. A. Tolosa): *neuro-radiologista; **assistente extranumerário. 
ciação dos resultados operatórios, a demonstração do restabelecimento da corrente sangüinea no vaso operado é obrigatória para que possa ser estabelecida relação de causa e efeito entre o tratamento e a eventual recuperação funcional do paciente ${ }^{2,5}$. Para isso, é preciso demonstrar angiogràficamente que havia oclusão vascular e, depois, que o fluxo sangüineo fôra restabelecido. Estas duas verificaçōes angiográficas consistem, em última análise, no reconhecimento da existência, ou não, de obstrução arterial patológica.

A existência de obstrução arterial não é suficiente, por si só, para indicação de uma intervenção cirúrgica, entre outras razões, porque em determinadas circunstâncias, a oclusão de uma artéria pode ser completamente assintomática. A oclusão de uma ou mesmo de ambas as artérias carótidas internas pode não acarretar qualquer distúrbio neurológico desde que o polígono de Willis seja plenamente suficiente e seja satisfatório o débito sangüíneo pelas artérias vertebrais. No caso de oclusão carotídea unilateral, a suplência sangüínea é garantida, em geral, pela carótida contralateral, através da artéria comunicante anterior (fig. 1). Quando há oclusão carotídea bilateral, a irrigação do encéfalo estará na dependência do sistema vértebrobasilar e da perfeição do poligono arterial de Willis (fig. 2).
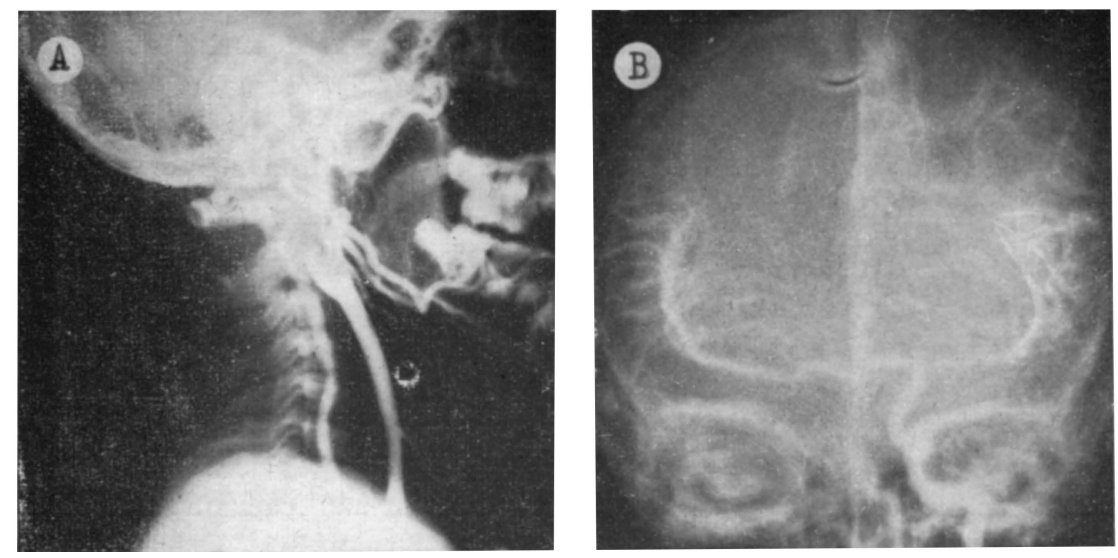

Fig. 1 - Oclusão de a. carótida interna e suplência através da a. comunicante anterior. $E m$, angiografia pela a. carótida primitiva direita mostrando oclusão da a. carótida interna logo acima da bifurcação. Em $B$, mesmo caso de $A$, angiografia carotídea controlateral, evidenciando a suplência sangüinea do hemisfério cerebral direito através da a. comunicante anterior.

Na maioria dos casos, o reconhecimento da oclusão trombótica completa de uma das carótidas internas não oferece dificuldade; no ponto correspondente à extremidade proximal do trombo a imagem arterial se interrompe de modo abrupto; na radiografia não são visíveis as artérias cerebrais; são 

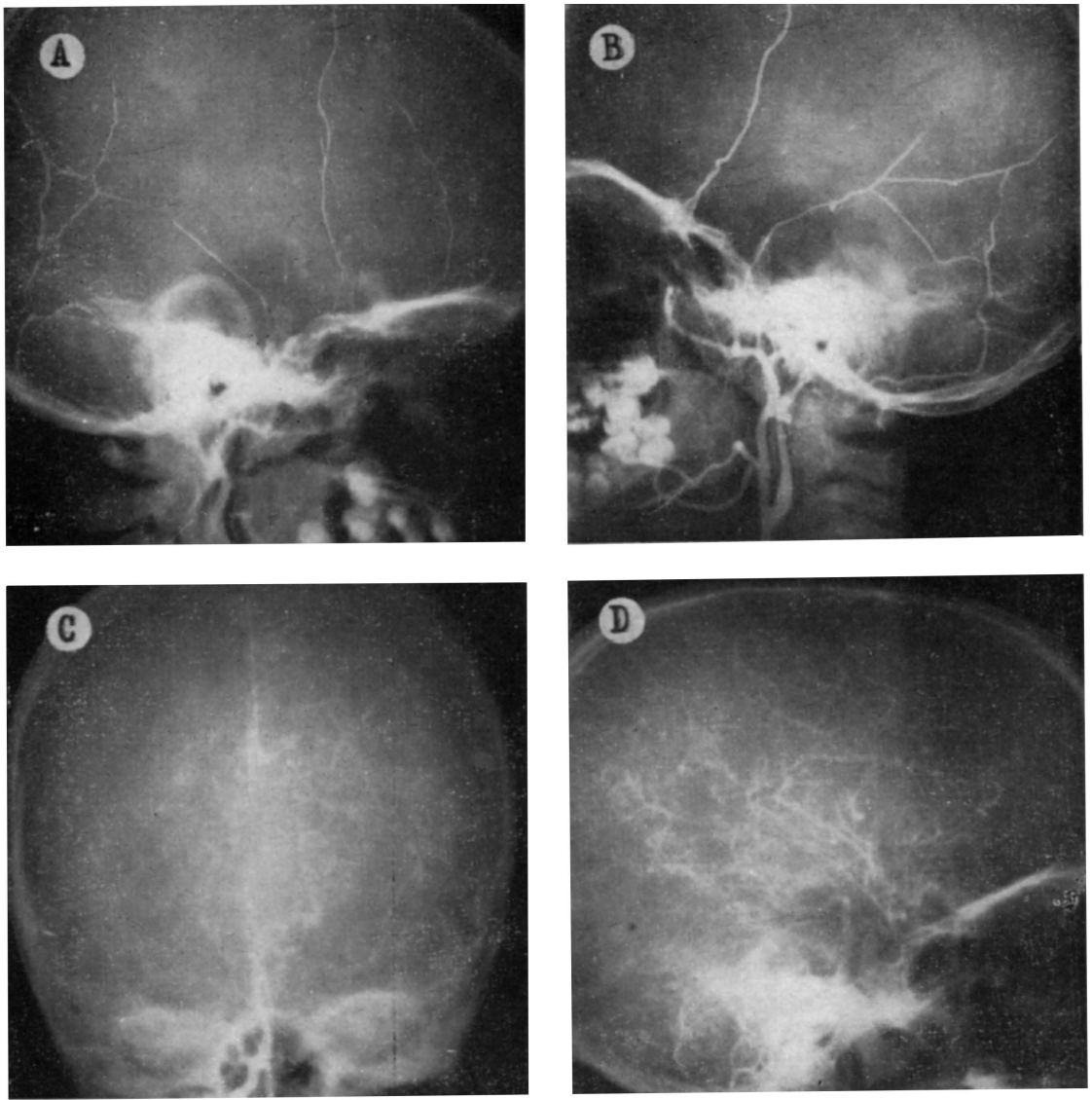

Fig. 2 - Oclusão bilateral da a. carótida interna e suplência a cargo do sistema vértebro-basilar. $\operatorname{Em} A$ e $B$, angiografia bilateral demonstrando oclusão da $a$. carótiala interna de ambos os lados; em $C$ e $D$, mesmo caso de $A$ e $B$, mostrando a visibilizaçio de todo o sistema arterial vértebro-carotídeo, pelo contraste injetado na a. vertebral direita.

visibilizados apenas ramos da carótida externa, sendo a artéria trombosada representada por um côto de forma variável (fig. 3). Côto de extremidade côncava sugere em geral oclusão por êmbolo (fig. 4).

Por outro lado, há oclusões arteriais cuja origem não patológica é prontamente denunciada, tão típico é seu aspecto arteriográfico. É o caso, por exemplo, da oclusão carotídea devida a descolamento da íntima em conseqüência de punção defeituosa; além do aspecto regularmente convexo da extremidade do "côto arterial", aparece a imagem da artéria vertebral ipsilateral, conseqüência do refluxo da substância radiopaca (fig. 5). Oưras 

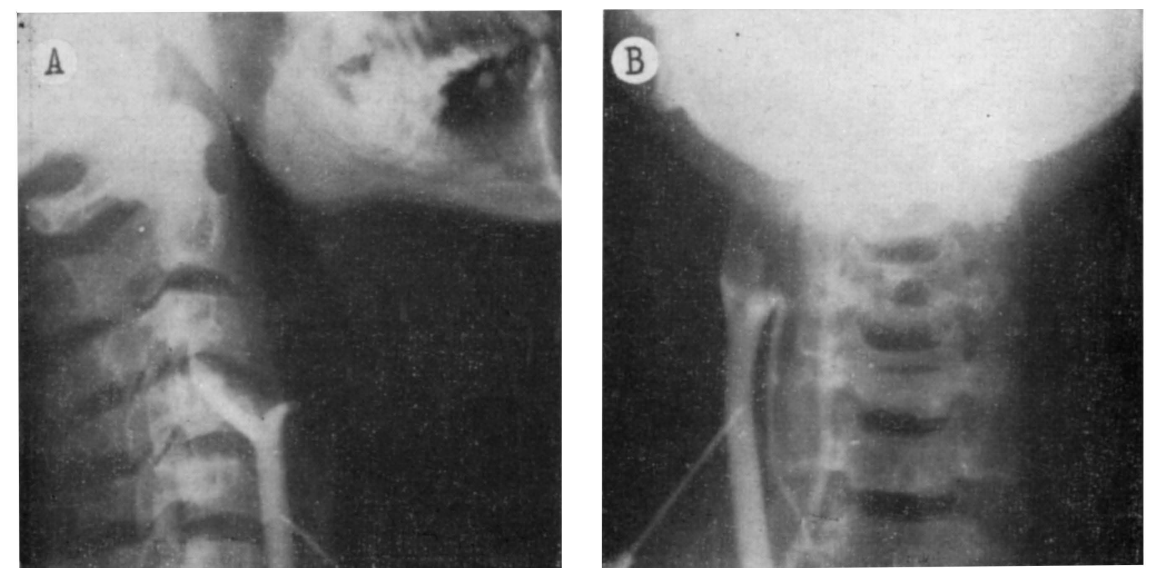

Fig. 3 - Angiografia pela a. carótida primitiva direita mostrando oclusão dêsse vaso ao nivel da bifurcação. Note-se, em $B$, o enchimento da a. vertebral direita em virtude do fluxo retrógrado na a. carótida primitiva.

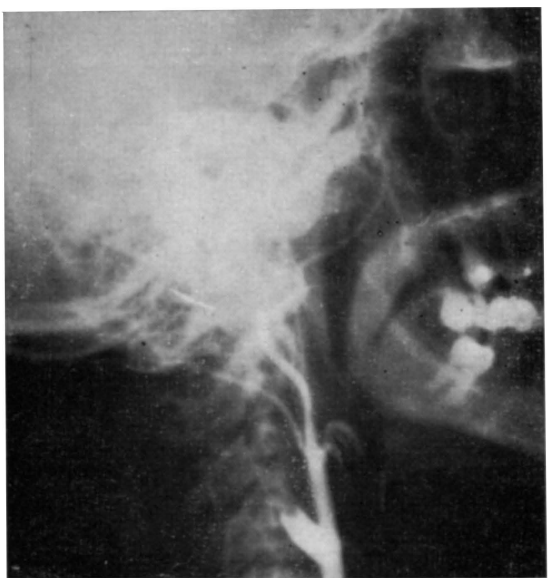

Fig. 4 - Extremidade côncava de côto de a. carótida interna sugerindo oclusão por êmbolo.

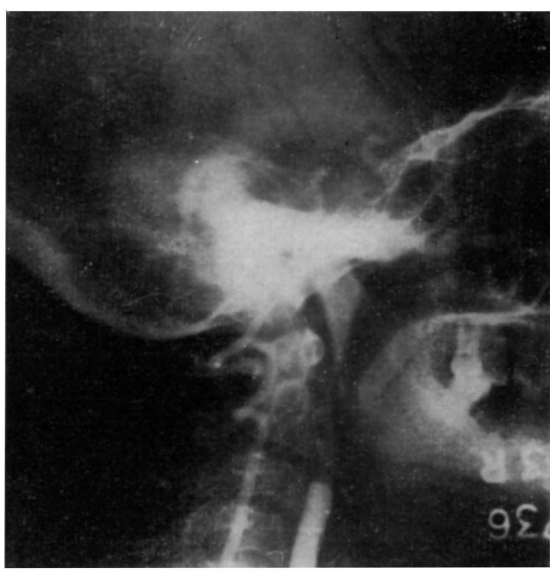

Fig. 5 -. Oclusão carotidea devida a descolamento da intima em conseqüência de punção defeituosa; note-se a imagem da a. vertebral ipsilateral, visibilizada graças ao fluxo retrógrado de contraste na a. carótida.

vêzes, porém, os aspectos angiográficos não são tão típicos, tornando difícil, senão impossível, a distinção entre uma oclusão arterial orgânica e duradoura e uma oclusão funcional e transitória. Dificuldades da mesma ordem podem ocorrer no diagnóstico diferencial entre uma oclusão arterial pato- 
lógica e uma oclusão artificial decorrente de defeito técnico. Mais difícil ainda, a nosso ver, é a avaliação da importância de uma redução de calibre arterial (estenose), verificada angiogràficamente. Finalmente, deve ser consignada a impossibilidade de distinguir uma oclusão adquirida de uma anomalia do polígono de Willis.

Por isso, julgamos oportuno êste trabalho cujo alvo principal é o de chamar a atenção para as dificuldades com que podem se defrontar os neurorradiologistas no diagnóstico das oclusōes arteriais e analisar o valor dos recursos disponíveis para vencê-las. Na época atual, quando a cirurgia vascular cerebral está em voga, êste trabalho se reveste de valor prático, pois, tendo por escôpo o aprimoramento do diagnóstico, poderá influir favoràvelmente no critério de seleção dos pacientes a serem submetidos a tratamento cirúrgico.

\section{MATERIAL}

Nosso material consta de 101 casos com oclusōes arteriais completas e 6 casos de estenose de maior ou menor segmento da artéria carótida interna (quadro 1). Em 74 casos a oclusão se encontrava nas artérias carótidas, sendo bilateral em 5; em 4 a oclusão se localizava na carótida primitiva. Nos 27 casos restantes, tratava-se de oclusões de artérias intracranianas: em 15 dêstes havia obstrução da artéria cerebral média; em 10 achava-se ocluida a artéria cerebral anterior; em um foi possível demonstrar oclusão subtotal do segmento pré-comunicante da artéria cerebral posterior $\left(P_{1}\right)$; em um encontrava-se ocluída a artéria cerebral média do lado examinado e ambas as artérias cerebrais anteriores.

Oclusões arteriais completas $\ldots \ldots \ldots \ldots \ldots \ldots \ldots$

carótida primitiva $\ldots \ldots \ldots \ldots \ldots \ldots$

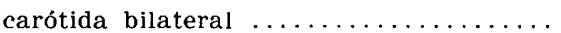

carótida interna (intracraniana) .......

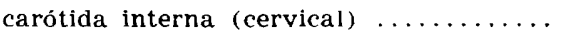

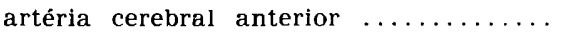

artéria cerebral média $\ldots \ldots \ldots \ldots \ldots \ldots$

artéria cerebral posterior $\ldots \ldots \ldots \ldots \ldots$

artéria cerebral anterior e média
4 casos

5 casos

12 casos

53 casos

10 casos

15 casos

1 caso

1 caso

Oclusões arteriais incompletas

101 casos

carótida interna (cervical)

carótida interna (intracraniana) .......

3 casos

3 casos

Quadro 1 - Freqüência de oclusão das diferentes artérias do sistema carótidovertebral.

Dos 70 casos com oclusão da artéria carótida interna, em 53 a oclusão estava localizada no segmento cervical dessa artéria, em 12 na sua porção intracraniana e em 5 era bilateral. Dos 53 pacientes com oclusão dessa artéria em nivel cervical, em 10 o exame radiológico foi repetido após variado número de dias; em 29 dêstes casos foi feita injeção de contraste também na artéria carótida contralateral e/ou 
na artéria vertebral; em 5 pacientes com estreitamento progressivo da carótida interna até a base do crânio não foi tomada nenhuma medida esclarecedora. No restante dêsses casos foi possivel prescindir de qualquer confirmação em vista do aspecto típico do côto arterial. Dos 15 casos de oclusão da artéria cerebral média, em 8 a oclusão se encontrava na origem dêsse vaso; em 7 a oclusão se encontrava na porção terminal do tronco principal, sendo visiveis alguns de seus ramos. Dos 10 casos de oclusão da artéria cerebral anterior, em 6 o vaso encontrava-se ocluído na origem, em 3 existia pequeno côto, em um não foi contrastado o ramo pericalosu. Dos 6 casos de estenose de maior ou menor segmento da artéria carótida interna, 3 apresentavam estreitamente de 0 a $2 \mathrm{~cm}$ de extensão em seu trajeto cervical e os outros no segmento intracraniano.

A revisão dêsse masterial mostrou que, se em boa parte dos casos o diagnóstico de oclusão arterial não oferece dificuldade, o mesmo, entretanto, não se verifica em outros. O estreitamento progressivo de uma carótida interna tanto pode ser orgânico como funcional, duradouro ou fugaz, devido ou não a defeito de técnica. Em boa parte dêsses casos persistem dúvidas mesmo após repetição do exame ou depois de angiografia contralateral. A falta de ramificação da a. cerebral média pode ser de origem orgānica ou funcional, podendo ainda ser devida a defeito de técnica (disparo precoce); a presença de ramos dessa artéria quando não seja contrastado o tronco principal pode ser devida a enchimento retrógrado dêsses ramos através de anastomoses superficiais, bem como a enchimento tardio devido a estenose do tronco principal ou ainda a um defeito de técnica (disparo retardado). Éstes e outros problemas devem ser resolvidos em boa parte dos casos quando se trata de estabelecer o diagnóstico de oclusão arterial.

\section{COMENTARIOS}

Para maior clareza e a fim de esquematizar o assunto não nos deteremos em considerações sôbre as oclusões patológicas ou artificiais de diagnóstico indiscutível; analisaremos sucessivamente as diferentes dificuldades que podem ocorrer no diagnóstico diferencial das oclusões arteriais e, em seguida, a solução aconselhável para tais dificuldades.

\section{Distinção entre obstrução arterial verdadeira e oclusão artificial.}

A distinção entre obstrução arterial verdadeira e falsa oclusão causada por defeito de técnica é sempre possível e, a nosso ver, objetiva e segura. Já ficou dito que, quando além da ausência das imagens dos vasos cerebrais, a arteriografia mostra um côto de carótida interna denunciando um trombo ou um êmbolo, o diagnóstico não oferece dificuldade alguma, sendo possível ainda, até certo ponto, verificar a extensão do segmento arterial bloqueado. A interrupção da imagem arterial ao nivel do segmento pré-comunicante da artéria cerebral anterior em uma angiografia carotidea, e a visibilização do segmento pós-comunicante desta artéria em angiografia contralateral define uma oclusão limitada ao segmento pré-comunicante. Da mesma forma, a ausência da imagem de uma artéria cerebral posterior em angiografia do sistema vértebro-basilar e a presença da imagem dessa artéria em angiografia carotídea do lado correspondente caracteriza oclusão arterial restrita ao segmento pré-comunicante da artéria cerebral posterior. O mesmo raciocínio se aplica a uma oclusão parcial como a da figura 6 . 

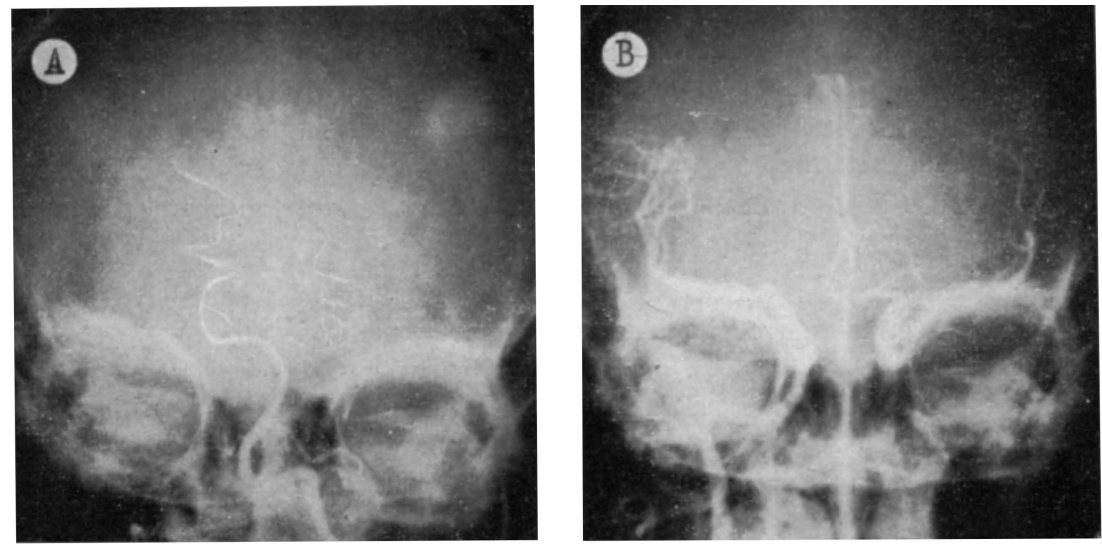

Fig. 6 - Estenose do segmento pré-comunicante $\left(P_{1}\right)$ da a. cerebral posterior esquerda; em $A$, angiografia pela a. vertebral esquerda, mostrando a $a$. cerebral posterior esquerda mal contrastada e com $P_{1}$ de calibre muito menor do que seu homônimo; em B, angiografia pela a. carótida direita, mostrando o segmento pós-comunicante da a. cerebral posterior esquerda com calibre normal.

Também em caso de falsa oclusão, o reconhecimento da verdadeira causa da falta de imagens das artérias cerebrais não constitui problema quando, além do crânio, a radiografia apanha suficiente extensão da região cervical para que uma injeção para-arterial ou intramural de contraste (fig. 7) seja visivel. A falta dos referidos elementos característicos, no arteriograma de
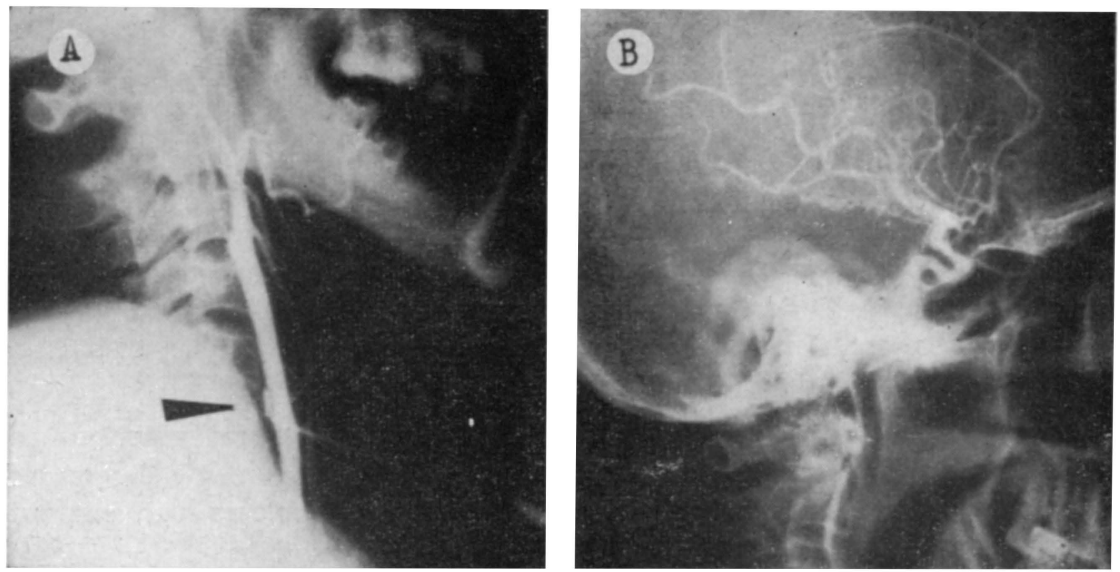

$H^{\prime} \imath g .7$ - Espasmo retlexo deviao a punçao dejeıtuosa; em $A$, punço muraı (seta) da a. carótida primitiva e imagem filiforme da a. carótida interna; em $B$, fase ulterior da mesma série mostrando os vasos cerebrais bem contrastados. 
rotina, torna necessária mais uma injeção de contraste para radiografar a região cervical e pôr, assim, a descoberto a causa da ausência das imagens das artérias cerebrais. Há muito tempo que temos utilizado esta fase de exame, mesmo nos pacientes de pescoço curto, nos quais somos obrigados a aumentar a distância objeto-filme. Aliás, a distorção da imagem resultante do aumento dessa distância tem sido parcialmente corrigida mediante aumento da distância foco-filme.

Disparo precoce dos raios $\mathrm{X}$, apanhando a coluna de contraste arterial antes que ela tenha atingido os vasos cerebrais poderia, em caso de radiografia única, simular oclusão arterial. Embora remota, essa possibilidade não deve ser olvidada particularmente por aquêles que, por falta de recursos, limitam a série a duas radiografias e, por falta de prática, poderiam disparar a primeira radiografia precocemente e a segunda tarde de mais, quando todo o contraste já tenha transposto o território vascular encefálico.

Uma regra prática consiste em testar a punção arterial antes de proceder a nova injeção de contraste; havendo qualquer dúvida quanto à qualidade da punção, a primeira coisa a fazer será corrigir a posição da agulha ou realizar nova punção.

II. Distinção entre obstrução orgânica e oclusão funcional da luz arterial.

Quando, ao invés de interrupção abrupta da imagem arterial, se observa estreitamento progressivo em extensão apreciável da luz vascular, o problema do diagnóstico diferencial torna-se mais complexo. A radiografia da região cervical, mostrando a ponta da agulha em posição correta e a ausência de contraste extra-arterial, poderá eliminar a possibilidade de oclusão artificial, mas não será suficiente para decidir entre obstrução orgânica da luz da artéria (por um trombo, por um êmbolo, ou por um espessamento difuso da íntima) e oclusão funcional por vasoconstrição reflexa. Não raro, a coexistência dêsses mecanismos de oclusão arterial torna ainda mais complexo o problema do diagnóstico diferencial.

Se tem sido posta em dúvida a ação de espasmos de artérias cerebrais na determinação de quadros neurológicos, a constrição arterial durante angiografia cerebral, desencadeada provàvelmente pela ação irritante da substância de contraste, é de observação corrente e de autenticidade indiscutível. O espasmo arterial pode ser intenso nos casos de punção trabalhosa quando a carótida é traumatizada por picadas repetidas.

Relativamente freqüente é o espasmo da artéria cerebral anterior sem redução apreciável do calibre da carótida interna. O mecanismo é ignorado mas a fugacidade dessa obliteração arterial denuncia, a nosso ver, sua origem eminentemente funcional (fig. 8).

A diminuição de calibre arterial nas vizinhanças de aneurisma rôto é outra modalidade de espasmo de artéria cerebral, comum nos casos de hemorragia meníngea recente (fig. 9). 

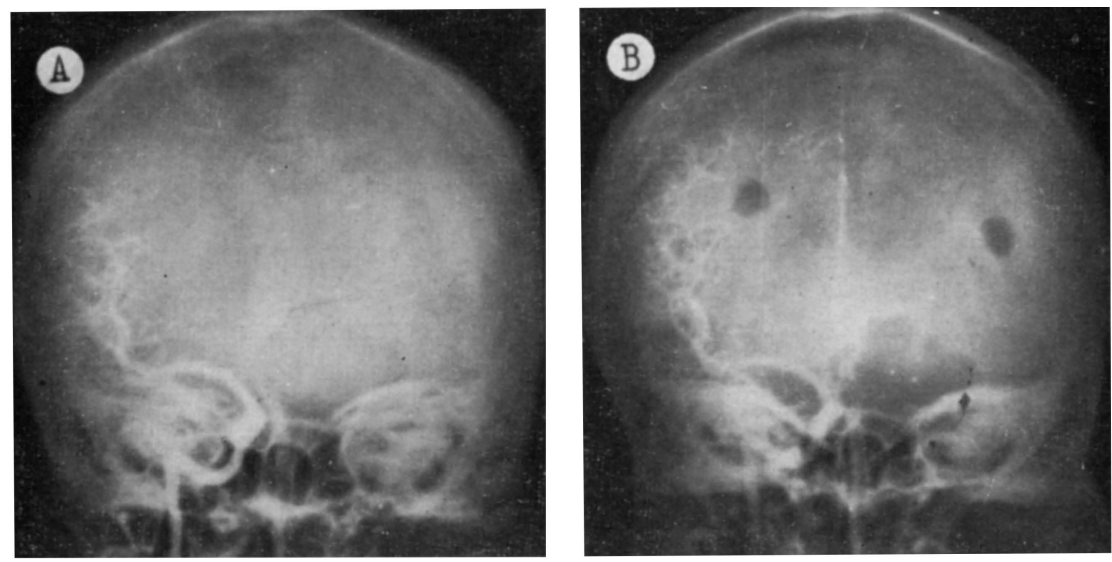

Fig. 8 - Oclusão transitória (espasmọ) da a. cerebral anterior; em A, ausência de imagem da a. cerebral anterior direita; em $B$, arteringrafia do mesmo paciente repetida dias após, mostrando a presença da a. cerebral anterior em todo seu trajeto.
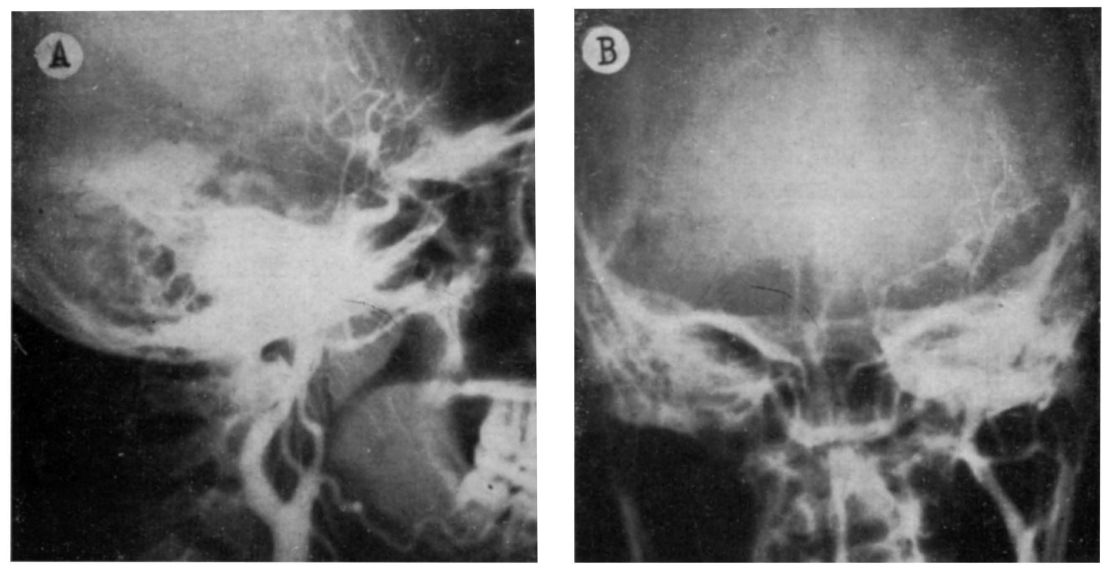

Fig. 9 - Incidência lateral e sagital de arı̀riografia carotídea, mostrando acentuada redução do calibre das artérias cerebral anterior e média, bem como do segmento intracraniano da a. carótida interna em caso de aneurisma da a. cerebral média.

O caráter temporário da oclusão ou da diminuição de calibre arterial atesta sua origem funcional, mas não elimina a possibilidade de um processo orgânico concomitante. A duração da constrição arterial é bastante variável; assim, a ausência e a presença de uma artéria cerebral pode ser observada em radiografias sucessivas de uma mesma série angiográfica, ao passo 
que a redução de calibre arterial nas proximidades de aneurisma rôto perdura por dias e, às vêzes, até por semanas. Pelo que acaba de ser exposto verifica-se que a caracterização da gênese funcional ou não de uma constrição arterial pode exigir a repetição, uma ou mais vêzes, de exame angiográfico.

A persistência de uma oclusão em séries angiográficas repetidas no mesmo dia ou em dias diferentes não é apanágio das obstruções orgânicas porque os mesmos fatôres que determinaram espasmo arterial por ocasião de uma primeira injeção de contraste podem atuar na ocasião de sua repetição. Da mesma forma, o aparecimento da imagem de uma artéria antes ausente, em uma repetição de angiografia não constitui documento do caráter funcional da oclusão, pôsto que, um trombo pode sofrer recanalização.

A infiltração do gânglio estrelado com novocaína tem sido recomendada como recurso para combater a vasoconstrição reflexa. Também a administração de papaverina, inclusive por via carotídea, pode ser usada com o mesmo fim. Não temos experiência com êsses recursos. $O$ emprêgo da hiperpressão pulmonar durante a injeção da substância radiopaca pode ser de valia em virtude de tornar as artérias mais intensamente contrastadas.

\section{Diagnóstico das estenoses arteriais segmentares.}

O reconhecimento de uma estenose arterial não constitui problema; uma artéria que, em dado ponto de seu trajeto se adelgaça e depois de maior ou menor extensão torna a engrossar, apresenta uma estenose. Estenose arterial pode ser congênita e resultante de anomalia do desenvolvimento ou adquirida. Tarefa mais dificil do que sua demonstração angio-
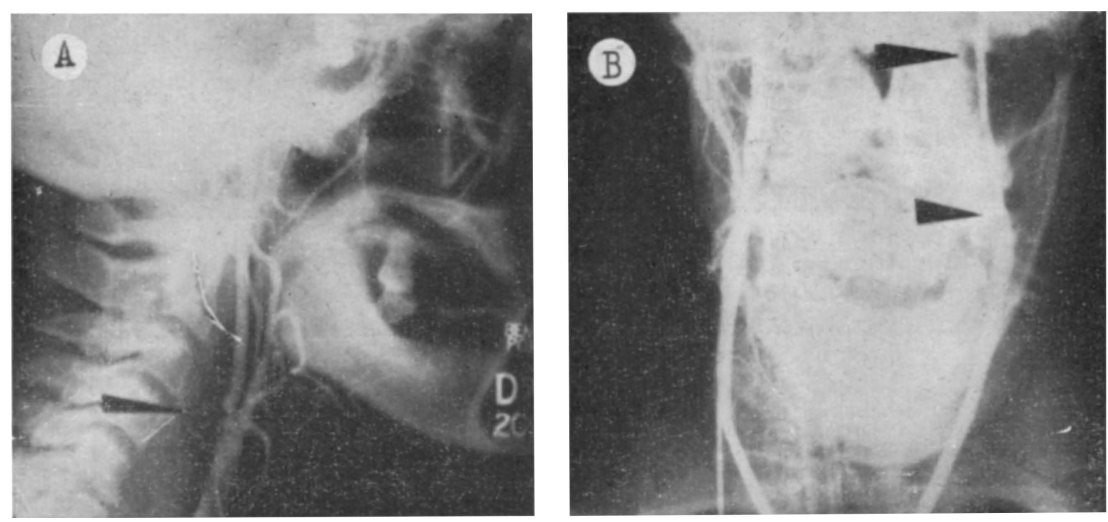

Fig. 10 - Estreitamentos arteriais. Em A, estenose em anel (seta) na origem $d a$ a. carótida interna; em $B$, estenose, em extenso segmento (setas), da $a$. carótida interna esquerda revelada por angiografia pela a. carótida direita rnm hinornrossãn nulmonav 
gráfica é a avaliação do papel que uma estenose arterial desempenha ou pode vir a desempenhar na ocorrência, atual ou futura, de manifestações indicadoras de comprometimento encefálico. Conseqüentemente, o diagnóstico diferencial das estenoses arteriais poderá desempenhar importante papel na indicação do tratamento cirúrgico e na modalidade de intervenção aplicável em cada caso. Um ateroma que diminui a luz vascular de modo irregular e excêntrico (fig. $10 \mathrm{~A}$ ) é fàcilmente distinguível de uma anomalia de desenvolvimento (fig. $10 \mathrm{~B}$ ). Outras vêzes, entretanto, não sendo típico o quadro angiográfico, o especialista deverá valer-se dos dados clínicos e, se necessário, recorrer ao estudo do defeito em exames sucessivos. A repetição da angiografia poderá demonstrar o caráter progressivo de uma redução de calibre arterial, o que constitui, a nosso ver, a melhor indicação para o tratamento cirúrgico.

\section{Distinção entre ausência congênita e oclusão arterial adquirida.}

Nas artérias ou segmentos arteriais que entram na constituição do polígono de Willis o reconhecimento da falta desta ou daquela parte é sempre difícil e pràticamente impossivel a não ser que haja um côto, sempre sugestivo de processo adquirido.

A oclusão ou ausência de uma das artérias comunicantes do polígono de Willis não pode ser reconhecida pela angiografia como é feita comumente, pôsto que, seu aparecimento nas arteriografias não é obrigatório. Em tais casos a pan-angiografia cerebral ${ }^{11}$ poderá constituir recurso de inestimável valor.

\section{RESUMO}

Este trabalho versa sôbre o diagnóstico especifico das causas da oclusão carotídea ou de uma das principais artérias intracranianas. Éle é baseado em 101 casos nos quais uma ou mais artérias acima referidas foram consideradas como ocluídas em conseqüência de causa patológica e 6 casos de estenose arterial de maior ou menor extensão.

A fim de sistematizar o estudo do diagnóstico diferencial, foram incluídos casos de oclusões artificiais. São postas em relêvo as dificuldades que podem ocorrer nas diferentes etapas do diagnóstico específico de uma oclusão arterial, bem como os recursos empregados para superá-las.

Para maior clareza, os diferentes itens relativos ao diagnóstico angiográfico das oclusões arteriais em aprêço foram esquematizados em: 1) distinção entre obstrução arterial verdadeira e oclusão artificial; 2) distinção entre obstrução orgânica e oclusão funcional da luz arterial; 3) diagnóstico das estenoses arteriais segmentares; 4) distinção entre ausência congênita e oclusão adquirida de uma artéria, particularmente no que se refere às partes constituintes do polígono de Willis. 


\begin{abstract}
SUMMARY
Arterial occlusion of the carotid-vertebral system. Problems concerned with the angiographic diagnosis.
\end{abstract}

This paper deals with the specific diagnoses of the causes and mechanisms involved in the occlusion of the carotids or one of the major intracranial arteries.

It is based on a series of 101 cases in which one or more of the above mentioned arteries were considered as occluded, the occlusion being of a pathologic origin. Artificial occlusion of the carotid and vertebral arteries as well as intracranial ones was also taken into account.

Difficulties which may arise in every step of the differential diagnosis of arterial occlusion are pointed out, as are technical resources which help to avoid such difficulties.

In order to render the report more practical the items concerned with angiographic diagnosis of occlusion of the intracranial and extracranial arteries of the brain are schematized as follows: 1) distinction between lasting and transitory non-pathologic occlusion; 2) distinction between organic and functional occlusion of an artery; 3) recognition of arterial narrowing; 4) distinction between congenital absence and acquired occlusion of an artery, specially one of the parts of the arterial circle of the base.

\title{
REFERENCIAS
}

1. CARREA, R.; MOLINS, M.; MURPHY, G. - Surgical treatment of spontaneous thrombosis of the internal carotid artery in the neck. Acta Neurol. Latinoamer., 1:71, 1955. 2. De BAKEY, M. E.; CRAWFORD, E. N.; COOLEY, D. A.; MORRIS, G. C. - Surgical considerations of occlusive disease of innominate, carotid and vertebral arteries. Ann. Surg., 149:690, 1959. 3. ELVIDGE, A. R.; WERNER, A. - Hemiplegy and thrombosis of the internal carotid system. Arch. Neurol. a. Psychiat., 66:752, 1951. 4. ISCH, F. - Essai clinique sur l'hemiplegie par trombose de la carotide interne ou de ses branches. Thèse, Strasbourg, 1950. 5. JACKSON, I. J.; FROMM, S. M. - Observations on patency of cervical carotid artery following surgical treatment for thrombosis. J. Neurosurg., 14:529, 1957. 6. JOHNSON, H. C.; WALKER, A. E. - The angiographic diagnosis of spontaneous thrombosis of the internal and common carotid arteries. J. Neurosurg., 8:631, 1951.7 . LYONS, C.; GALBRAITH, J. G. - Surgical treatment of the internal carotid artery occlusion. Geriatrics, 13:1, 1958. 8. MURPHEY, F.; MILLER, J. H. - Carotid insufficiency diagnosis and surgical treatment: report of twenty-one cases. J. Neurosurg., 16:1, 1959. 9. RISER, M.; LAZORTHES, G.; GERAUD, J.; RIBAUT, L.; ANDUZE-ARCHER, H. - Trombose de la carotide interne. Neurochir. (Paris), 1:309, 1955. 10. STRULLY, J. K.; ELLIOT, S. H.; BLAKENBERG, H. W. - Thrombo-endarterectomy for thrombosis of the internal carotid artery in the neck. J. Neurosurg., 10:474, 1953. 11. ZACLIS, J. - Visibilização radiográfica de todo o sistema vascular encefálico mediante injeção de contraste em uma única artéria: pan-angiografia cerebral. Arq. Neuro-Psiquiat., 17:1-22, 1959. 